\title{
Impact of Integration Processes and Preventive Development of Infrastructure on Local Food Markets Performance
}

\author{
Trineeva L.T.* \\ Voronezh State University of Engineering Technologies \\ Voronezh, Russia \\ E-mail: lapa82@list.ru
}

Kolesova E.Yu.

Voronezh State University of Engineering Technologies Voronezh, Russia

E-mail: kolesova.vgta@yandex.ru

Ustyugova I.E.

Voronezh State University of Engineering Technologies Voronezh, Russia

E-mail: ystugova@yandex.ru

\author{
Belyaeva E.A. \\ Voronezh State University of Engineering Technologies \\ Voronezh, Russia \\ E-mail: ekblv@mail.ru \\ Loskutov S.A. \\ Voronezh State University of Engineering Technologies \\ Voronezh, Russia \\ E-mail: uopioe@yandex.ru \\ Chigirina T.Yu. \\ Voronezh State University of Engineering Technologies \\ Voronezh, Russia \\ E-mail: chigirina-t@ rambler.ru
}

\begin{abstract}
Local food markets are the interaction of local producers and consumers of food products. Over a long period, scientists have identified demand, supply, prices and competition as the main elements of market conditions, and producers and consumers of goods which are specific to a particular market as the main participants of market interaction. A distinctive feature of the local food market is the concentration of market agents in a certain region and their interaction in accordance with the preconditions for the development of local communities that form the demand and supply of food products, taking into account the technological features of their production. The spread of integration processes leads to competition between integrated structures. Within the framework of alliances and partnerships, local market participants strengthen their competitive positions by combining resources, skills, and experience, i.e. competencies of participants. Food market actors have an opportunity to fight for international leadership and gain market positions that ensure the sustainability of their future position. At the same time, cooperation is observed between participants who previously competed with each other. The conceptual regulations of the functioning and development of the local food industry market represent a combination of scientists' views on the problem of integrational interaction of regional actors in the form of holdings, clusters, networks and other geographicallylocalized structures, with regional economic participants that form and regulate supply and demand in the food industry market in accordance with the regional development targets, taking into account the limitations and preconditions to satisfy population demands for high-quality own-produced food.
\end{abstract}

Keywords - local food markets, integration, infrastructure development, holdings.

\section{INTRODUCTION}

The solution to the food problem is impossible without the effective functioning of the food markets of the country and regions but the rational organization of the market space. The geographical features of Russia in solving the problem of its food security bring the development of local food markets to the first place. The performance problems of these markets are not fully understood, and a number of regulations for organizing the existing production and market infrastructure are debatable. It means that a special attention should be paid to the applied organizational and methodological tools for the development of the local food market, which allows solving the most important problems.

This set of issues is covered in the scientific works of the following Russian scientists: Cherepova R., Hitskova I., Matveeva A., Plahotnikova P., Zhakhova N., Stepanova T., Kurnosova A., Hasanova A.

The aim of the work is to study, justify and clarify theoretical aspects of local food markets functioning in the framework of the development of integration processes and clarify the specific characteristics of infrastructure associations.

\section{METHODOLOGY}

While writing the paper, a comprehensive scientific and methodological approach was used, including the following methods: descriptions, comparisons, analysis and synthesis, analogies, deductions, generalizations and graphic. 


\section{DISCUSSION}

The market in the most general sense is the interaction of producers and consumers. Projecting this approach on the food market and clarifying it, R. Cherepov gave the following definition: "the food market is a set of socio-economic relations in the sphere of exchange through which the sale of food products is carried out". Note that in our opinion the key aspect in the given definition is the social significance of exchange processes in food markets.

The economic mechanism of the food market cited by the author is considered as a system of economic levers, incentives and regulatory methods aimed at creating favorable environment for the effective functioning of its participants [2].

I. Hitskov carried out systematic studies, which concluded that the food market operates according to three laws: the law of value, the law of demand and the law of supply. The first law is involved in the formation of the average price level in the market and affects the level of socially necessary production costs. The laws of supply and demand determine the ratio of cash and commodity flows, supply and demand in the market and form the price.

A. Matveev, P. Plahotnikov, R. Cherepov and other authors [1], involved in the study of food markets, name a number of characteristics of their performance. The main of them are summarized (Figure 1).

It should be noted that the last sign in modern institutional conditions has practically lost its relevance. Moreover, in the "era of the decline of liberalism" (as presented by R. Nizhegorodtsev), state regulation of the economy, including the formation and development of local food markets, is being updated. N. Zhakhov, relying on the work of neoinstitutionalists, while substantiating the need for state regulation of the agro-industrial complex indicates that "the economy is not closed system, but inextricably linked to social relations, politics and ideology. The mechanism of free competition in such a system does not fulfill the role of an equilibrium regulator, since the market is structurally transformed by monopolies and the state. Therefore, to achieve economic equilibrium, state regulation is necessary."

According to T. Stepanova and A. Kurnosov, nowadays "the Russian food market contains only some elements that are the essence of the market mechanism. However, this does not form a unified economic system. The state consciously and purposefully participates in the formation of the food market. Moreover, it creates favorable conditions for its work and is based on the laws of commodity production" [3]

Agreeing with the statements discussed above, we note that in modern conditions the sign of state policy in the framework of food markets performance is transformed into a protectionism policy.

The necessity to develop and protect mechanisms for the domestic food market performance is especially relevant in the context of the sanctions policy and the violation of traditionally established economic relations in the field of export-import food supplies [12].

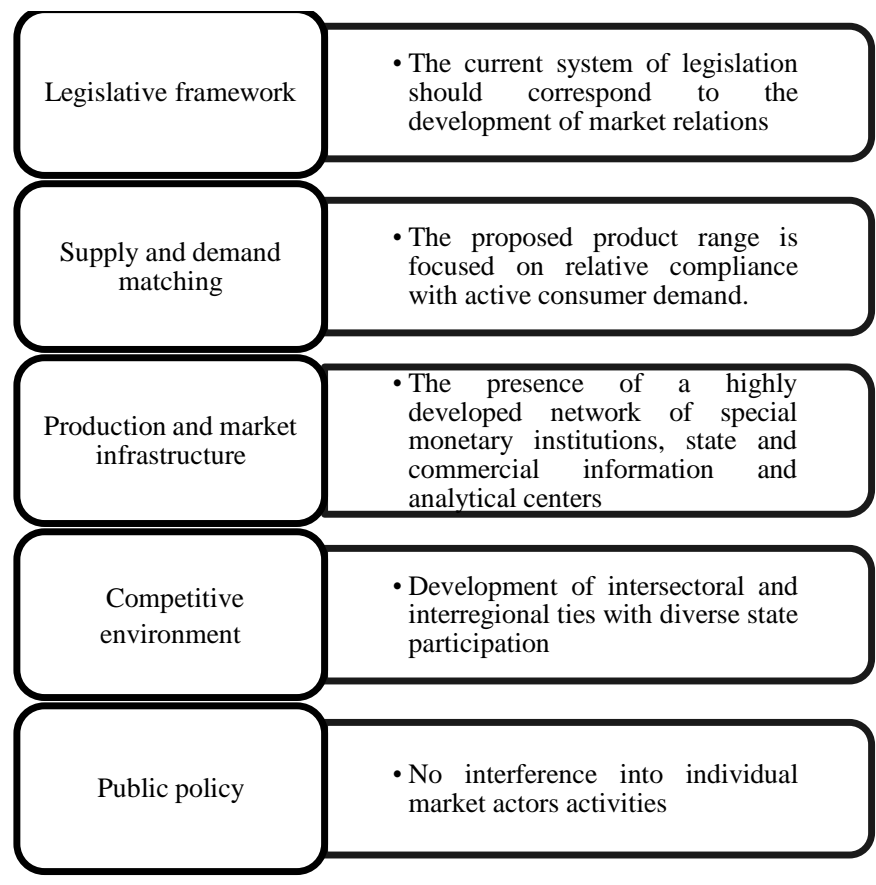

Fig. 1. The main characteristics of food markets

A. Hasanov says that preconditions and environment are necessary for the normal performance of the food market. Complementing the list he proposed, we made the following clarifications (Figure 2).

A feature of the local food market is the concentration of market agents on the territory of a certain region and their interaction in accordance with the restrictions, as well as the preconditions for the development of local communities, which form the demand and supply of food products taking into account the technological features of their production.

In condition of modern development of the global economy, the movement of more than half of the world gross product along the value chain and its implementation take place in the structure of integration ties. In Russia, the importance of integration ties is especially high, because they help to minimize the level of uncertainty. Moreover, competition turns into cooperation by establishing contacts with consumers, government agencies and the public and other agents; facilitates the mechanism of technological reequipment, the introduction of innovations and their diffusion [8].

From the position of the stakeholder, integration interaction is a reaction of regional economic participants interested in its development to the resource problems, which is implemented in the desire to establish mutually beneficial ties and cooperation. The majority of researchers, as a rule, call business, government, civil society institutions, and the population as the main stakeholder groups [15].

Taking into account that socio-economic agents can be divided into two groups of agents that make decisions; and "influence agents" whose solutions are not targeted, we note that the integration interaction occurs with the participation of agents of each of the given above types (Figure 3). 


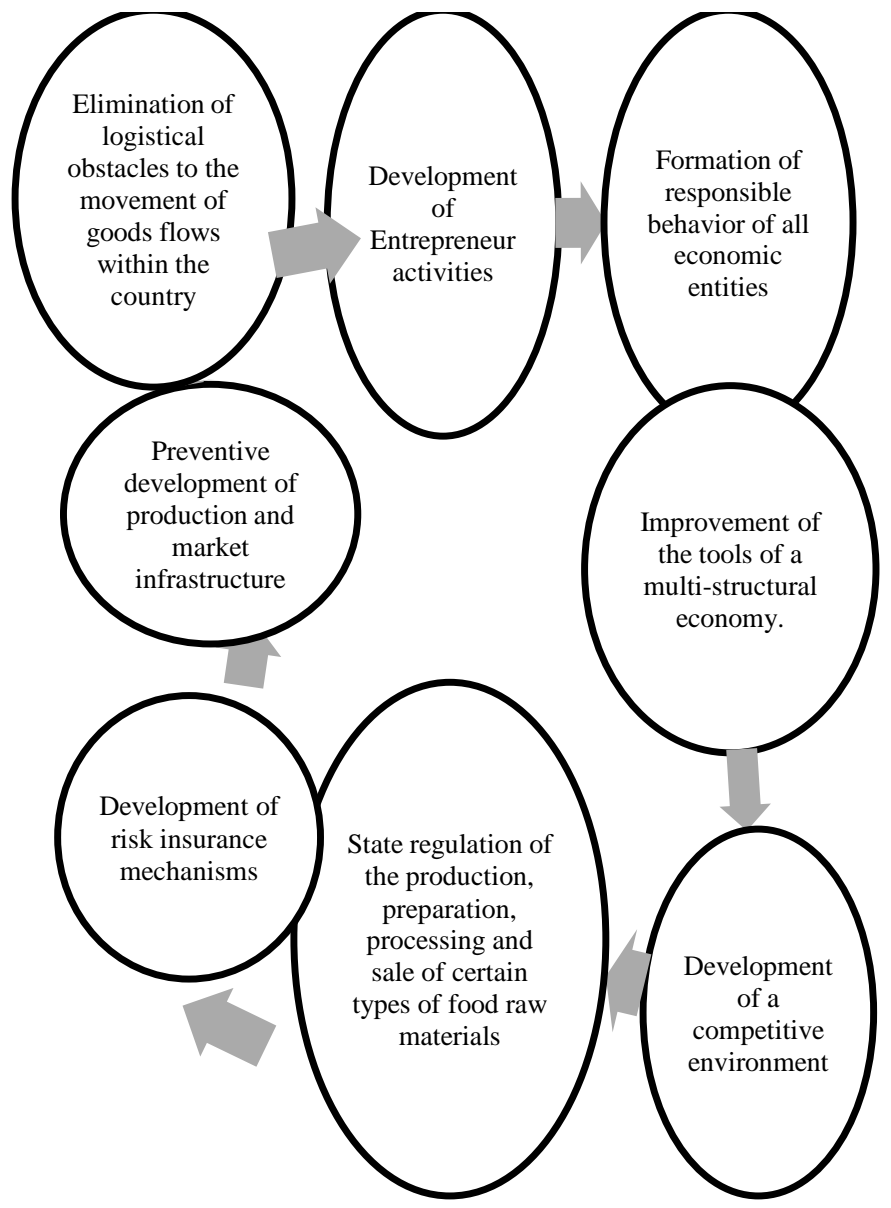

Fig. 2. Clarified preconditions and operating environment of the food market

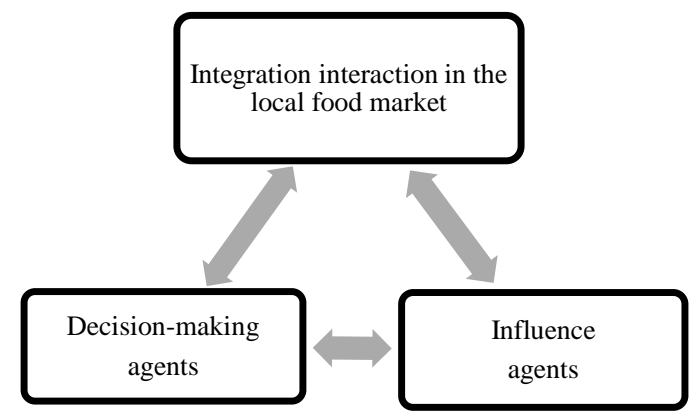

Fig. 3. The scheme of integration interaction in the process of formation of socio-economic relations in the local food market.

After integration processes have been formed, a long-term convergence of strategic goals between their participants takes place. In this case pure competition is transferred into one of the types of cooperation. The range of opportunities of such cooperation varies from weak interaction to direct management, where market relations transfer into intracompany deliveries based on concluded contracts [10].

Throughout the entire period of transformation of the national economy, which began in the 90s, the main form of participants' integration in local food markets was holdings, many of which are still operating in accordance with the temporary regulations adopted in 1994.
The appearance of numerous holdings contributed to the formation of the main element of the market conditions which is supply, since holdings accounted for the largest share of marketable products represented on local food markets. As an example, we consider agricultural production by categories of enterprises in one of the main agricultural regions of the country - in the Voronezh region (Figure 4).

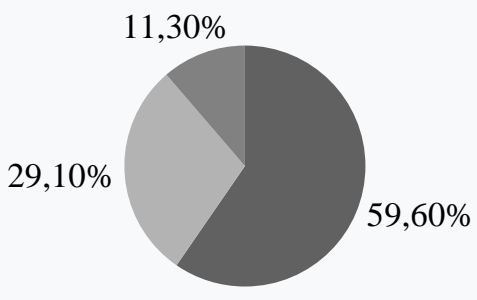

- Big agricultural organizations

- Agricultural Enterprises

- Personal enterprises of population

Fig. 4. The structure of agricultural production by farm categories in 2018 in the Voronezh region

The main share of the gross and marketable products of the local agricultural market, including food market, is made by large organizations, which fully confirms the movement towards integrated cross-sectoral integration.

The food market infrastructure can be divided into functional and system-forming. Functional contains market participants who are involved directly into the process of commodity exchange: banking, insurance, consulting companies, agricultural enterprises, processing complexes and food industry enterprises, procurement, insurance organizations, trade centers, public catering and other entities. The system-forming infrastructure includes market participants who form the process of commodity circulation: wholesale food markets, exchanges, terminals, distribution centers, cold storage plants, elevators, etc. [5].

\section{RESULTS}

In order to solve the research problems, we have developed an actual functional and system-forming infrastructure of the local food market, specific features, which are shown in Figure 5.

The differentiation of agents is applicable only to the regional economy because with the help of economic, administrative, regulatory, financial, and other instruments, the state power executive, media, population, consolidation of producers, and other groups of regional economic participants can significantly influence the formation and market development of a product specific to a given region (the production of which is effectively specialized in a substantial share of local goods production).

The positioning of the state power executive is based on participation as agents regulating supply and demand in the development and implementation of the development strategy 
of a region, food supply policy for the population of a region and other documents regulating food consumption [11].

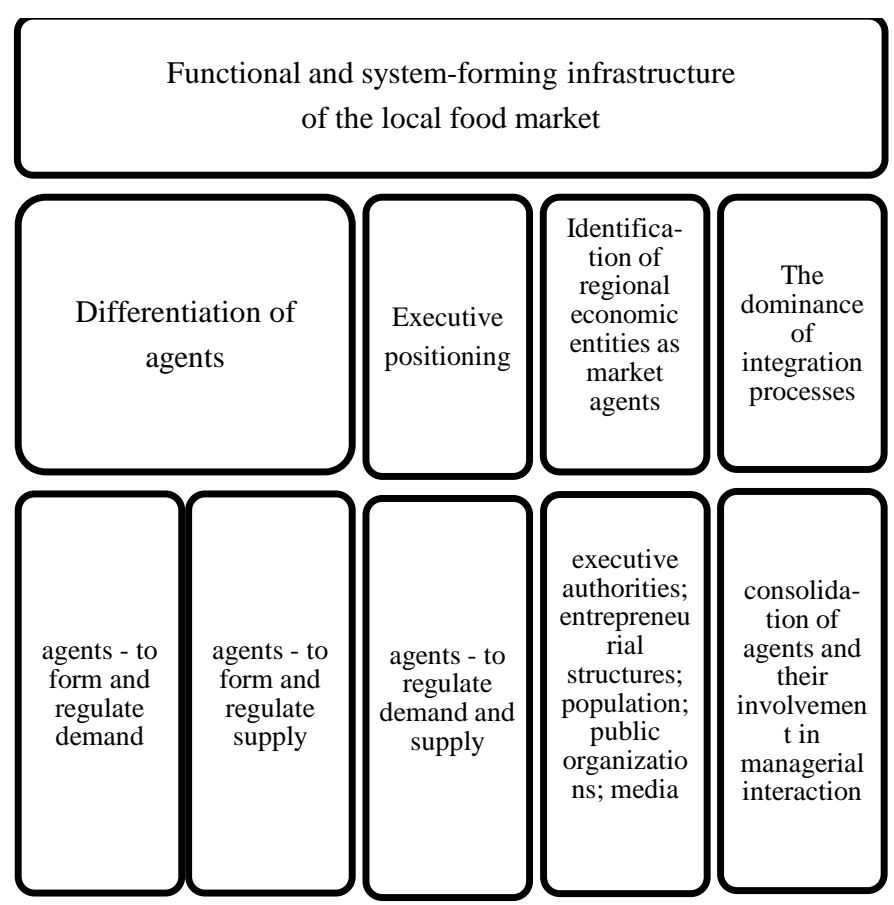

Fig. 5. Specific features of the functional and system-forming infrastructure of the local food market.

The role-based identification of regional economic participants, caused by their involvement in managerial interaction, is aimed at developing the local food market. The study identified five groups of regional economic participants involved into the local food market performance: state power executive; entrepreneurial structures; population; public organizations; mass media.

The dominance of integration processes, which are the nature of the emergence of consolidation of entrepreneurial structures, generalized organizations and other subjects of the regional economy, is the basis for their involvement in managerial interaction [15].

New institutional conditions are appeared in the development of the local food market on the base of the intensification of integration interaction.

This statement is the result of a syllogism: 1) the local food market is a modern institution; 2) integration processes lead to the formation and development of local food markets, as they mediate the involvement of regional economic participants in managerial interaction and activate it; 3) the integration interaction of regional economic participants involved in the formation and development of the local food market is a fact of institutional changes. [4]

The need to develop local food markets is obvious and axiomatic. Based on this thesis, the study determined the conditions for the development of local food markets (table 1).

The forms of integration interaction of regional economic participants who encourage the development of the local food industry market are vertically integrated holdings, research and production clusters, producer networks, and competency networks [6].

TABLE I. CONDITIONS FOR LOCAL FOOD MARKETS DEVELOPMENT

\begin{tabular}{|l|l|}
\hline Condition type & \multicolumn{1}{|c|}{ Content } \\
\hline Sufficient & $\begin{array}{l}\text { the presence of organizational and economic } \\
\text { preconditions for the specialization of the region in } \\
\text { the production of goods that determine the market }\end{array}$ \\
\hline Necessary & integration networking in the most promising forms \\
\hline
\end{tabular}

The desire of regional economic participants to avoid transaction costs leads to the following consequences: (1) autonomously functioning regional economic participants create integrated structures of a corporate (holding) type; (2) corporate structures and regional economic participants maintain autonomy form integrated cluster-type structures; (3) all participants of the regional economy, including the population and state power executive, are involved in network structures, which are the top of evolution of integration interaction forms [9].

The disadvantage of the current structure of the local food industry market, considered on the example of the Voronezh region, is underestimated role of educational, research and development organizations, and as a result it hinders the development of such promising forms of integration interaction of its participants as scientific and production clusters, networks of manufacturers and consumers, etc.

The development of integration processes in the form of associations, alliances, strategic partners, clusters, networks, etc. is a means of ensuring the competitiveness of residents and, in general, the regional economy, represented by local markets of goods specific to a given territory.

The spread of integration processes leads to the fact that there is competition between integrated structures. At the same time, within the framework of alliances and partnerships, local market participants strengthen their competitive positions by combining resources, skills, experience, i.e. competencies of participants. Food market actors get the opportunity to fight for international leadership, gain market positions that ensure the sustainability of their future entrepreneurial position. In this case, cooperation between participants who previously competed with each other can be noted [4].

The result of the integrated process is the formation and development of consolidation of market counterparties, which in their present or future activities are able to receive and realize the benefits of integration, which initially served as the motives for their interaction.

\section{CONCLUSION}

The conceptual regulations of the functioning and development of the local food industry market represent a set of author's views on the problem of integration interaction of regional actors in the form of holdings, clusters, networks and other geographically-localized structures. It is necessary to note that regional economic participants form and regulate supply and demand in the food industry market in accordance with the regional development targets, taking into account the limitations and preconditions to satisfy population demand for high-quality food products of own production. 


\section{References}

[1] A.I. Altukhov, V.I. Nechaev, Economic problems of the innovative development of the grain product subcomplex of Russia, Monograph. Moscow: Publ. House Nasirddinova V.V., 2015, 477 p.

[2] S.T. Antipov, L.V. Antipova, I.P. Bogomolova, Food Security: Forecasting, Monitoring and Evaluation of Agricultural Development Trends, Monograph. Voronezh: Voronezh State Univer., 2015, 368 p.

[3] E.A. Belyaeva, A.G. Tkachev, "World trends in the formation of the assortment of bakery products", FES: Finance, Econ., Strategy, no. 7, pp. $40-45,2018$.

[4] I.P. Bogomolova, A.V. Bogomolov, E.A. Belimova, Improving the management of the resource potential of baking enterprises in conditions of ensuring food security, Improving the management of the resource potential of baking enterprises in conditions of ensuring food security, Monograph. Voronezh: Voronezh. state Univer. of Engineer. technol., 2017, 79 p.

[5] I.P. Bogomolova, V.M. Bautin, O.G. Stukalo et al., Innovative management tools to ensure the disruptive nature of the development of the Russian economy in the context of import substitution, Monograph. Voronezh: VGUIT, 2018, 209 p.

[6] V.A. Kamneva, L.T. Trineeva, "The enrichment of wheat flour with salts of iron and folic acid, as one of the ways to increase sales volumes", 69 p., 2015 [Innovative technologies of the Russian agro-industrial complex in 2015, Mater. of the III conf. as part of the 9th Int. Biotechnological Forum-Exhibition "RosBioTech - 2015". Moscow.

[7] O.M. Omelchenko, I.N. Vasilenko, A.V. Bogomolov, "Improving the management of integration and cooperation processes in the grain processing sector of the agro-industrial complex in the context of ensuring balanced development", FES: Finance, Econ., Strategy, no. 7, pp. 46-56, 2018. Voronezh.

[8] "Prospects for the spatial development of the agro-industrial complex and rural territories", Materials of the All-Russian scientific and practical conference, Voronezh, March 29, 2019. Voronezh: FSBI NIIEEOAPK CCHR Russia, 2019. 277 p.

[9] L.T. Pechenaya, S.V. Tolkacheva, I.E. Domarev, "Evaluation of the technical level of raw materials storage and processing enterprises as the basis of their competitiveness and sustainable development", Econ. yesterday, today, tomorrow, no. 10, 2016.

[10] O.V. Sidorenko, Formation and development of grain product subcomplex: theory, methodology, practice: monograph. Eagle: Publ. House of the Fed. State Budget Ed. Establishment of Higher Ed. in the Oryol GAU, 2015, 192 p.

[11] Economic aspects of the development of the food industry in the context of import substitution and digitalization of the modern industry, Collective monography, under the sci. ed. of E.V. Savvateeva. Moscow: Sci. Consultant Publ. House, 2019, 216 p.

[12] I.P. Bogomolova, A.V. Kotarev, I.N. Vasilenko, "Trends and prospects for the development of the livestock industry of the meat and food subcomplex in terms of resource saving and public administration", Proc. of the Voronezh State Univer. of Engineer. Technol., vol. 81, no. 2, pp. 301-311, 2019.

[13] El.A. Gurkovskaya, A.A. Larionova, N.A. Zaitseva, O.S. Prantsuz, A.N. Zhavnerov, A.A. Semenova, "Assessment of the economic effect of the introduction of innovations in the investment and construction cycle" EurAsian J. of BioSci., no. 13, pp. 2041-2049, 2019.

[14] I.E. Ustyugova, L.T. Trineeva, E.Yu. Kolesova, "The concept of formation and development trends of the local food industry market in the context of intensifying the integration interaction of its participants", Bull. of the Voronezh State Univer. of Engineer. Technol., vol. 81, no. 3, pp. 276-281, 2019.

[15] M.S. Asmolova, S.V. Dedov, "The algorithm to ensure and implement the strategy of the effective management of innovation processes", Proc. of the Voronezh State Univer. of Engineer. Technol., vol. 80, no. 4, pp. $436-440,2018$. 